\title{
CRITICISMS AND DISCUSSIONS.
}

\section{EASY NON-EUCLID.}

In England Euclid is used as a synonym for elementary geometry. Let us use non-Euclid for elementary synthetic non-Euclidean geometry.

In ordinary Archimedean geometry, if we know the angle-sum in a single rectilineal triangle, we know whether the geometry be Euclidean or non-Euclidean; if the sect from the vertex of the right angle to the mid-point of the hypotenuse partition a rightangled isosceles triangle into two congruent right-angled isosceles triangles, which it does if that sect be half the hypotenuse, then space is Euclidean.

At last then we are able to understand, to marvel at the prophetic, the mystic clairvoyant genius of Dante, the voice of ten silent centuries, in connecting with the wisdom of Solomon and the special opportunity vouchsafed Solomon by God, a question whose answer would have established the case of Euclidean geometry seven centuries before its birth, or the case of non-Euclidean geometry three thousand years before its creation by Bolyai.

I Kings iii. 5 is: In Gibeon the Lord appeared to Solomon in a dream by night: and God said, Ask what I shall give thee.

Then says Dante of his asking,

"'Twas not to know the number in which are

Or if in semicircle can be made

Triangle so that it have no right angle."

[O se del mezzo cerchio far si puote

Triangol si, ch'un retto non avesse.]

Par. C. XIII, 101-102.

How unexpected, how startling this! Ever overlooked, yet now when found how strangely reinforced by Dante's ranking in 
the fourth canto of the "Divina Commedia," with Cæsar, greatest of men, among exalted personages

$$
\begin{aligned}
& \text { "... who slow their eyes around } \\
& \text { Majestically moved, and in their port } \\
& \text { Bore eminent authority," }
\end{aligned}
$$

Hippocrates of Chios who squared the lune, nearest that ever man came to the quadrature of the circle until finally Bolyai squared it in non-Euclid and Lindemann proved no man could square it in Euclid; and then Euclid himself, the geometer, the elementist, preemptor, by his unprovable postulate, of the commonly credited universe, Euclidean space; and then Ptolemy, first of the long line of those who have tried by proof to answer the question Dante says Solomon might have asked God and did not, a question crucial as to whether Euclid's or Bolyai's space holds the actual world, the real thing.

Of course the treatise of the great astronomer, purporting to prove the parallel-postulate, miscarried, and hundreds after him spent in vain their brains in like attempts. What vast effort has been wasted in this chimerical hope, says Poincaré, is truly unimaginable.

Yet according to my genial friend Francis C. Russell, it is all so easy that he is only prevented from letting out the secret by fear lest he offend!

In the last number of The Monist, April, I909, p. 294, he says: "The proof that the two secondary triangles are exactly equal to one another, that they are right-angled and isosceles.... is so simple in more than one way, that it would be almost an imputation upon the reader to spread it before him."

By what he does spread before us let us judge of the quality of his supposed proof. He prints from Lobatchevsky: "24. The farther parallel lines are prolonged on the side of their parallelism, the more they approach one another." Yet he misses the point, that in this non-Euclid, parallelism is a sensed relation. As shown by Lobachevsky's very first figure, which he reproduces, page 29I, through every point two intersecting straight lines are parallel to the same straight line in opposite senses. How then could any one pervert the theorem "15. Two straight lines which are parallel to a third in the same sense (toward the same side) are also parallel to one another" into applying to two straight lines parallel to a third in opposite senses? Yet this he solemnly does, saying, p. 302, "This looks to me very much like a proof that in all cases the angle of 
parallelism is a right angle," and then impales himself on the following reductio ad absurdum: "Now by the very same course of deduction the line KAK' is shown to be parallel to HAH' and to EAE', in spite of the rather important feature that they cut one another at A."

With this before us, I think we can never hope from Mr. Russell a validly justified answer to Dante's question for Solomon, but his article is interesting if only for its very liberal quotations from the only English translation of Lobatchevsky, now rare, and for its amplification of a definition of the plane and the straight line given in 1904 as $\S 59$, p. 29 , of the first edition of Halsted's Rational Geometry.

The article is as follows: "59. If A, B, C be any three points not costraight, then (by the method used in $5^{8}$ ) we can construct a point $B^{\prime \prime}$ such that $A B^{\prime \prime}$ is identical with $A B$ and $C B^{\prime \prime}$ is identical with $\mathrm{CB}$ :

"Therefore a point D such that no other point whatsoever, say $D^{\prime \prime}$, gives $A D^{\prime \prime}$ identical with $A D$ and $C D^{\prime \prime}$ identical with $C D$, must be costraight with AC."

The following have been given as definitions:

"If $A$ and $B$ are two distinct points, the straight $A B$ is the aggregate of points $P$ for none of which is there any point $Q$ such that $Q A$ is identical with $P A$ and $Q B$ identical with $P B$.

"If $A, B, C$ are distinct points not costraight, the plane $A B C$ is the aggregate of points $P$ for none of which is there any point $Q$ such that $Q A$ is identical with $P A, Q B$ identical with $P B$, and $Q C$ identical with PC."

Since in the book no use is made of the parallel postulate until after this article, we see Mr. Russell was mistaken in saying we have no applicable criterion showing that his straight, Euclid's and Lobatchevsky's are one and the same. But of course the alternative deduction he gives lacks this advantage, since in it he has unconsciously assumed the parallel postulate, assuming that every three points are costraight or concyclic. He also makes the unnecessary assumptions of the compasses (Halsted, Geom., Appendix II, and Euclid I, 20, etc.).

Our sects, point-pairs alike or differing as to congruence, he calls intervals, our definition he speaks of as "a definition which so far as I know is a new one," and in trying to show "how the ruler may be derived by means of the compass (sic) alone," he does not 
know that we have supplanted the compasses by a far simpler instrument, the sect-carrier, and that again by the unitsect-carrier.

George Bruce Halsted.

Greeley, Col.

\section{CONSTRUCTION OF THE STRAIGHT LINE.}

IN COMMENT ON MR. FRANCIS C. RUSSELL'S ARTICLE" "A MODERN ZENO."

Mathematicians will take an interest in Francis C. Russell's attack on the mathematical system of Lobatchevsky, whom he calls a "modern Zeno." If Mr. Russell is right we shall have to grant that there is a flaw in the arguments of Lobatchevsky on which he bases a new geometry that in contrast to Euclid's does not acknowledge the postulate of parallel lines.

Mr. Chas. S. Peirce in a letter to Mr. Russell thinks that he (Mr. Russell) overshot the mark. He says: "Those two lines cutting each other are not parallel and his (Lobatchevsky's) defining them as parallel to the third was in obvious contradiction to the proposition that two straight lines both parallel to a third are necessarily parallel to each other. I press the question, Why did you not content yourself with this obvious proof of the incorrectness of his proposition No. 25? The answer seems to me obvious. If you had done that your readers would have at once perceived that Lobatchevsky merely made a slip of the pen and meant that two straight lines parallel to a third toward the same side are parallel to each other."

Though Mr. Russell may have gone too far, he has called attention to a mistake which ought to be corrected, and Mr. Charles S. Peirce, in thoughtful consideration of the difficulty which puzzled Mr. Russell, points out the flaw.

But metageometricians are not so considerate. They claim that he has thoroughly misunderstood non-Euclidean geometry. We publish in the present number two criticisms, one by Professor $G$. B. Halsted, the other by W. H. Bussey, assistant professor of mathematics at the University of Minnesota.

Metageometricians are a hotheaded race and display sometimes all the characteristics of sectarian fanatics. To them it is quite clear that there may be two straight lines through one and the same point which do not coincide and yet are both parallel to a third

${ }^{1}$ See the April number of The Monist. 